\title{
E-GOVERNMENT: AN E-REVERSE AUCTION CASE STUDY
}

\author{
Steve Jones \\ Conwy County Borough Council
}

Ray Hackney, Zahir Irani

Brunel University

\section{ABSTRACT}

This paper presents the findings from an exploratory in-depth case study with regard to eReverse Auctions (eRAs) in the UK public sector. These findings highlight that eRAs can improve procurement processes, realise cost savings and reduce delivery times. The research also notes that eRAs can produce dis-benefits, including poor buyer and supplier relationships and social implications. The paper elicits lessons learnt from the case study analysis. These are presented with the aim to inform theory and practice.

Key Words: e-Government, e-Reverse Auctions, Procurement, Case Study.

\section{INTRODUCTION}

e-Government (eGov) is now endemic in worldwide public sector organisations. eGov has enabled the UK public sector to become more efficient and effective. This has been due to improvements to internal and external processes and activities (Wilson and Game, 2007). One new and emerging area of eGov is e-Reverse Auctions (eRAs). In simple terms, an eRA is an Internet-based, online and dynamic auction, in which suppliers bid against each other to provide products at the lowest cost to the purchaser. eRAs have been successful in the private sector and have significantly reduced procurement costs and delivery times (Wagner and Schwab, 2004). Some authors now argue that eRAs should be able to produce similar results in the public sector and improve the contribution of eGov to organisational efficiency and effectiveness (Sashi and O'Leary, 2002; Beall, et al., 2003).

Procurement is now a key and current issue in the UK public sector. This is primarily a result of a directive from UK central government for the UK public sector to reduce costs and become more efficient (Gershon, 2004). eRAs therefore, may assist with this objective and furthermore, may also help to improve the actual procurement process. However, against this backdrop of perceived efficiencies and benefits from eRAs, some authors have argued that there can also be important dis-benefits (Beall, et al., 2003; Jap, 2003; Emiliani, 2006). These include poor sourcing decisions, poor buyer and supplier relationships, higher costs, less cooperative suppliers and longer delivery times. Lapiedra et al. (2004) note that some suppliers that had won eRAs, by bidding below their own profit margins, had subsequently, more than 
recovered these costs, during subsequent negotiations. Furthermore, eRAs are not suited to all situations (Smeltzer and Karr, 2003). The key issue therefore, is whether eRAs deliver cost savings, value and benefits to the public sector.

There is literature in relation to eRAs at the macro-level with regard to the private sector. However, there is a paucity of literature specifically related to eRAs in the public sector. This is especially the case with regard to individual case studies. This paper therefore, investigates how eRAs impact upon organisational efficiency in one public sector organisation. This is undertaken by exploring eRAs in the public sector via an interpretive case study. The aim is to understand and gather knowledge regarding eRAs and to present findings to inform theory and practice.

\section{CONTEXT OF THE RESEARCH}

The seminal Gershon report concerning UK public sector efficiency (Gershon, 2004) and the national procurement strategy from the Office of the Deputy Prime Minister (ODPM, 2003) both require the UK public sector to improve procurement to obtain efficiencies. Central government has set a significant financial target of $£ 120 \mathrm{~m}$ for procurement savings in 2008 . Successful eRAs may contribute to this target. However, eRAs are relatively new to the public sector and therefore, should be carefully considered.

A recent central government initiative, Making the Connections, further requires UK public sector organisations to maximise efficiency gains through collaboration and co-operation. Any benefits from eRAs may be increased and improved if the eRA is either undertaken in collaboration with other public sector bodies or any eRA findings are shared between organisations. eRAs undertaken collaboratively, by several public sector organisations, would demonstrate to central government a willingness to co-operate. Indeed, outwardly, this approach appears to have many benefits, including risk reduction, risk spread, improved contract negotiations and product demand aggregation to lower both procurement and product costs. Moreover, most UK sector organisations usually purchase the same goods from the same suppliers. Many public sector organisations have a professional and corporate approach to purchasing, including procurement strategies and a dedicated team of purchasing professionals. Any findings from an eRA, if shared, would be of interest and perhaps, of benefit to other public sector organisations.

Clearly, eRAs change the traditional procurement process. Any change that may affect this approach is worthy of exploration to understand the impact. This paper therefore, explores whether efficiency gains can be achieved through the use of eRAs via a case study. The research methodology is discussed in the next section.

\section{METHODOLOGY}

The research subject, eRAs in the public sector, is a new and emerging area. The research is therefore, explorative. The research consists of an interpretive in-depth case study of a UK local authority in the tradition of Walsham (1995). The aim was to understand and gain insights into eRAs and to elicit lessons for theory and practice. 
The case study employs Grounded Theory (GT) developed by Glaser and Strauss (1967). GT is a research approach that aims to understand the phenomenon under study, which is grounded in the empirical data. GT is an inductive approach that is more likely to resemble organisational reality, rather than theory deduced and developed from concepts based on hard evidence. The aim is the creation of knowledge through case study research (Remenyi et al., 2002). Walsham (1995) contends that interpretive methods of IS research are aimed at producing an understanding of the context of the subject under study and can produce deep insights. Walsham (1995) further notes that whilst the findings are not necessarily generalisable, they may be generally useful.

The eRA explored in this research study was for the supply of IT equipment. Semi-structured interviews were undertaken with the purchasing manager (PM) and the information technology manager (ITM) in the case study organisation. The data was subsequently analysed using GT. Secondary data included documentary evidence, such as reports, memos and specifications.

\section{CASE STUDY FINDINGS}

The case study organisation reported that there is a need for the buyer to establish whether there is sufficient supplier interest before any eRA can be undertaken. Where this is not the case, the eRA should not proceed. The case study organisation was able to establish that there was sufficient market-place interest by undertaking market research.

As a public sector body, the case study organisation has to comply with the European Union (EU) Procurement Rules (Arrowsmith, 2002). This required the organisation to advertise the eRA and eRA contract in the European Journal and to follow the EU tender process. This can be lengthy and expensive, but was not a major issue in the case study.

The case study reported that it is vitally important for the buyer to have clear product specification and contract terms. It was noted that products with complex specifications and complex contract terms are more difficult to procure via an eRA. The case study organisation therefore, undertook a thorough internal product needs analysis, via a questionnaire, which led to the development of a comprehensive but simple specification for the IT equipment to be procured. This required the collection and analysis of user requirements and subsequent specification with regard to the equipment. Furthermore, the potential suppliers had to fully understand the specification and contract terms for the IT equipment. Unlike other products purchased by the case study organisation, IT equipment is purchased corporately and not by individual departments. Therefore, IT equipment numbers were already aggregated to make the contract more attractive to suppliers because of the greater sales numbers.

One important issue highlighted was that some of the best suppliers might decide not to bid at the eRA. This can lead to the buying organisation having to commit to a supply contract via the winning eRA bid. However, better prices and terms may be available elsewhere, but are unobtainable because the supplier with the lower price did not bid. It is also possible that a very good supplier, who bids, does not win. This supplier may loose by a very small monetary margin, buy may have other qualities, in addition to price, that would influence any decision to purchase. For example, an existing good relationship with the supplier, together with a commitment to improving the efficiency and effectiveness of the relationship, can be more 
important than the lowest price solutions. Unfortunately, for all concerned, it would not be possible to ignore the winning buyer and commission another supplier. Furthermore, even if this other supplier was prepared to reduce the price to match the winning bid, it would not be possible to adopt this approach due to EU regulations. This highlights that decisions based upon price alone, may not necessarily deliver the optimal solution.

The case reported that price is more important in eRAs than in any other product procurement situations. Other important criteria include service, claims and warranties, quality, location, and the technological capabilities of the equipment. Suppliers usually have account managers in place to deal with us buyers face-to-face.

The organisation reported that there was a concern in relation to the potential difficulty to ensure that the supplier has sufficient incentives to continue to provide an appropriate performance level, once the contract has been signed. This may be an issue towards the end of a long-term contract, especially if the supplier no longer wishes to supply the product to the buyer. There is also a concern in relation to the potential for a lack of value for money when the procurer is locked in to one supplier over a long period of time. Complacency can set in if another eRA is not undertaken to ensure that the product cost is still competitive, as prices may reduce elsewhere, but the supplier does not reduce the price.

Several risks associated with the contract award have been identified. These include insufficient contractual flexibility to meet changing product needs or any future collaboration and partnership needs, a lack of capacity to resource any future significant additional product numbers.

A great deal of work was undertaken to ensure that the eRA process and project was carried out properly and professionally. The contract was pro-actively managed to help ensure problems did not emerge. This was especially important, as there will be a significant cost and lengthy timescale to make any major changes to the existing contract or to undertake another eRA to replace the existing supplier to overcome any problems. It is important therefore, for buyers to understand that good working relationships are essential. Only a combination of both the eRA and subsequent successful supplier relationships is likely to deliver long-term and sustainable benefits.

It is important to ensure that appropriate internal communication takes place, both prior to and during, the decision-making phase. This will help ensure that the approved supplier is the most suitable one for stakeholders in the organisation. The case study reported that there has been a lack of effective engagement with stakeholders, which has caused some issues. The new supplier and associated new IT kit has been forced upon users without full consultation or a trial of the equipment. Furthermore, the implementation has not been split into steps. Instead, a full implementation of the IT equipment has been adopted. This has resulted in some social and human implications emerging, such as resistance to using the new equipment and resistance to change.

Although the case study organisation was unable to give specific figures, due to confidentiality issues, cashable savings have been achieved via the eRA. That is to say that the local authority is paying a reduced price for the IT equipment. Furthermore, other benefits have been identified, which are now being monitored. The case study organisation reported 
that the eRAs had been successful and had considerable benefits. Furthermore, the success of the eRA had led to the organisation highlighting that there are further opportunities to identify and undertake other eRA activities in relation to other equipment purchases.

\section{DISCUSSION}

The case study eRA was generally successful and illustrates that certain contextual conditions influence the success of any eRA. This finding concurs with authors such as Jap (2002), Beall et al. (2003) and Smeltzer and Karr (2003). These contextual conditions include a high volume of goods, perhaps generated by aggregating all organisational IT expenditure, favourable market conditions, high competition and products that are simple to specify.

It is important to define the scope of the eRA and set clear specifications and realistic targets. Local authorities need to identify the type of products that are conducive to successful eRAs and the processes that can be undertaken to achieve economies of scale. They should therefore, ensure that standardisation underpins any eRA specification. Product customisation should only occur in exceptional, properly considered and authorised cases. Also, each step of the process needs to be prepared, supported, and executed with thorough information sharing between both the buyer and supplier organisations. Not all products are well suited to eRAs. Products that are complex to specify are difficult to translate into unambiguous specifications. This has detrimental consequences for the efficiency of any eRA.

The success of the contract ultimately depends on the quality of services provided by the supplier. Therefore, there may be a need for service level agreements in the contract to help ensure good supplier performance. For example, targets to prevent delays in the renewal of equipment and mechanisms to maintain good communication. Others could include factors that measure the quality of services, measure user satisfaction with the supply contract and assess the status of the project.

Furthermore, it is important to undertake cost benefit analysis and monitor market costs to ensure that the contract continues to be competitive.

Future contracts should contain value for money mechanisms to enable costs to be benchmarked and externally validated. These mechanisms should extend to contractual change provisions. Also, there needs to be an effective management structure for the partnership between buyer and supplier. The way individuals undertake their roles and responsibilities in the procurement partnership is important and will heavily influence the success or otherwise, of the buyer and supplier relationship. This buyer and supplier relationship needs to be monitored and reviewed to ensure it continues to be effective. The costs of changing the existing supplier may be significant and inhibit the overall effectiveness of an eRA. For example, if an organisation is going to switch supplier every quarter, eRA may not be effective.

One important issue that should not be over-looked, is that product users should be involved at all stages of procurement project and not just the user requirement and specification stage. Users should be consulted and informed when the contract is awarded and involved in the deployment or rollout of the new product. This will help alleviate resistance to change and ensure that the procurement service and the equipment procured meets user requirements. One 
other emerging issue is that of a lack of face-to-face contact between buyer and supplier can be detrimental to any future supplier account management.

One area for consideration in the future is that of eRA collaboration between public sector bodies. Collaboration may improve the benefits from eRAs and reduce risks. For example, greater product aggregation, simplification, time and cost efficiencies. There is also, for the suppliers, the attraction of dealing with one large contract rather than several smaller contracts. Any supplier may be more inclined to bid for one large contract rather than several smaller ones. A public sector strategic procurement partnership may offer networking opportunities to improve public sector procurement practice.

Clearly, the case study organisation is satisfied that the decision to proceed with the eRA strategy was soundly based. Furthermore, that the procurement is operationally efficient and effective. Overall, the case study reports that the eRA procurement process was successful. The initiative resulted in with improvements to the procurement process, significant cost reduction, value for money and efficiencies.

\section{LESSONS}

The case study research and analysis has enabled the authors extrapolate lessons and these are now presented. Purchasing managers in the public sector need to ensure that the following conditions prevail to help ensure successful eRAs:

- appropriate product (highly standardized and simple to specify);

- appropriate organisation and structure (corporate purchasing approach);

- appropriate market conditions (sufficient competition, market interest, excess capacities);

- appropriate process (accurate needs analysis, indicative quantities or values, adequate pre-qualification and final selection of supplier);

- appropriate supplier management (clear, open, and candid communication)

- appropriate contract (one large contract, not several small contracts)

- appropriate value for money mechanisms (externally validated costs)

It is hoped that these lessons will be helpful and assist public sector organisations with future eRAs.

\section{CONCLUSIONS}

The aim of this study was to explore how eRAs impact on organisational efficiency in the public sector and to extrapolate lessons for theory and practice. The research illustrates that the key issues for successful eRAs are good preparation, strong market-conditions and simple specification. There can also be dis-benefits in relation to eRAs. These include social implications. However, if undertaken well, an eRA can lead to cost product cost reductions and significant improvements to public sector procurement efficiency. This enhances the contribution of eGov deployment in the public sector.

This is an exploratory study and further research is necessary. Future case studies should therefore, be undertaken. This research could include investigating larger eRAs in terms of 
product value and eRA that involve collaborative working and partnerships across the public sector.

\section{ACKNOWLEDGEMENTS}

The authors acknowledge the support from the Information Systems Evaluation and Integration Group (ISEing) which supported part of this work. ISEing was established at Brunel University Department of Information Systems and Computing, in December 2000, under a research grant from the UK Engineering and Physical Sciences Research Council (EPSRC: GR/R08025/01). Financial support to present this paper will come from the EPSRC funded 'e-Government Integration and Systems Evaluation (e-GISE)'. EPSRC Ref: [GR/T27020/01].

\section{References}

Arrowsmith, S. (2002) Electronic Reverse Auctions under the EC Public Procurement Rules. Public Procurement Research Group, University of Nottingham.

Beall, S., Carter, C., Carter, P. L., Germer, T. and Jap, S, (2003) The Role of Reverse Auctions in Strategic Sourcing. CAPS Research, http://www.capsresearch.org/publications/pdfs-protected/beall2003.pdf .

Gershon, P. (2004) Independent Review of Public Sector Efficiency: Releasing Resources to the Front Line. HM Treasury

Glaser, B. and Strauss, A. (1967) The Discovery of Grounded Theory: Strategies for Qualitative Research. Aldine Publishing Company, Chicago.

Jap, S. (2002) Online reverse auctions: issues, themes and prospects for the future. Journal of the Academy of Marketing Science 30 (4), 506-525.

Jap, S. (2003) An exploratory study of the introduction of online reverse auctions. Journal of Marketing 67 (3), 96-107.

Lapiedra, R., Smithson, S., Alegre, J. and Chiva, R. (2004) Role of information systems in the business network formation process: An empirical analysis of the automotive sector. The Journal of Enterprise Information Management 17 (3), 219-228.

Office of the Deputy Prime Minister (ODPM) (2003) One Year On: The National Strategy for e-Government. http://www.localegov.gov.uk/Nimoi/sites/ODMP/resources/local\%20egov\%201Year\%20On\%20Doc 21.pdf.

Remenyi, D., Money, A., Price, D. and Bannister, F. (2002) The Creation of Knowledge Through Case Study Research, Henley College Working Paper, WHP 2018.

Sashi, C. M. and O'Leary, B. (2002) The role of Internet auctions in the expansion of B2B markets. Industrial Marketing Management 31 (2), 103-110.

Smeltzer, L. R. and Karr, A. (2003) Electronic reverse auctions: promises, risks and conditions for success. Industrial Marketing Management 32 (6), 481-488.

Wagner, S. M. and Schwab, A. P. (2004) Setting the stage for successful electronic reverse auctions. Journal of Purchasing and Supply Management 10 (1), 11-26.

Walsham. G. (1995) Interpretive Case Studies in IS Research: Nature and Method, European Journal of Information Systems 4(2), 74-81.

Wilson, D. and Game, C. (2007) Local Government in the United Kingdom, Macmillan. 